\title{
Gestão de serviços de saúde: analisando a identidade na graduação
}

\author{
Health services management: analyzing its identity in \\ undergraduation
}

Mateus Aparecido de Faria', Analise de Jesus da Silva²

RESUMO O objetivo deste artigo é encontrar indicações no Projeto Político-Pedagógico da graduação em Gestão de Serviços de Saúde - versões 2008 e 2013 - sobre quais caminhos esse curso tem trilhado e com qual área de conhecimento mais se relaciona. Trata-se de pesquisa qualitativa documental cuja análise dos dados abordou três vertentes: administração, saúde coletiva e multidisciplinar. Além da busca argumentativa de defesa das três vertentes, tentou-se expandir o debate para outros campos de disputas que não o cotidiano do curso com o objetivo de fortalecer essa formação em saúde.

PALAVRAS-CHAVE Educação superior; Saúde pública; Universidades; Projetos; Gestão em saúde.

ABSTRACT This article aims to find clues in the Pedagogical Political Project of Health Services Management Undergraduation Course - versions 2008 and 2013 - as for which ways the Course has trodden and to which area of knowledge it relates more. This is a documental qualitative research whose analysis of materials focused threefold: Management, Collective Health and a multidisciplinary area. In addition to the argumentative search in defense of the three areas, it also tried to expand the debate to other fields of struggles than the everyday course so to strengthen this health formation.

1 Universidade Federal de Minas Gerais (UFMG), Escola de Enfermagem Belo Horizonte (MG), Brasil. mateusfaria18@gmail.com

2 Universidade Federal de Minas Gerais (UFMG), Faculdade de Educação, Departamento de Métodos e Técnicas de Ensino - Belo Horizonte (MG), Brasil. analisedasilva@gmail.com

KEYWORDS Education, Higher; Public health; Universities; Projects; Health management. 
1 São utilizadas cerca de doze denominações para o que chamamos aqui de PPC. Os nomes mais recorrentes são Projeto Político-Pedagógico (PPP) e Projeto Pedagógico de Curso (PPC) (LIMA, 2011). Apesar de o objeto de estudo desta pesquisa ser o PPC, entendemos que o caráter político desse importante instrumento de gestão universitária é inerente a qualquer proposta pedagógica e sua dizibilidade precisa ser praticada.

\section{Introdução}

A identidade de cursos é discutida na literatura como forma de expor, através de perspectivas críticas, os conflitos, conquistas e desafios enfrentados tanto por cursos tradicionais como pela pedagogia (SOUSA NETO, 2005; ROSA, 2007; MALACRIDA ET AL., 2013), pelas novas graduações em saúde (LIMA, 2009) ou pelos programas de pós-graduação (MARTINS, 1999).

Segundo Sousa Neto (2005), os estudos de identidade tentam explicitar não só discussões internas no desenvolvimento desses cursos como conflitos de interesses, principalmente no que se refere ao perfil do egresso, currículo adotado e comparações com outros cursos similares no País. Tal identidade é construída pelos diversos atores que se relacionam nesse cenário docentes, discentes e gestores (MALACRIDA ET AL., 2013) -, onde o Projeto PolíticoPedagógico (PPP) e documentos auxiliares formalizam e verbalizam as escolhas feitas em determinado tempo-espaço histórico e de forma coletiva (VEIGA, 2002, 2003; LIMA, 2009).

Quando o foco é deslocado para cursos na área da saúde, percebe-se uma existência bem consolidada da identidade do profissional pós-graduado, a exemplo dos campos da saúde pública, gerontologia e saúde coletiva. No entanto, a partir da criação dos novos cursos formadores desses profissionais no nível de graduação, surgiram também a necessidade de questionamentos do 'como, para quê, por quê, para quem' da implementação de tais iniciativas (BOSI; PAIM, 2010; RUELA, 2013). Tantos questionamentos, em um evidente cenário de incertezas, são necessários para a construção da identidade, entendida pelo viés histórico-social e reconstruída constantemente, uma vez que se somam formados na graduação e na pós ao campo identitário da profissão (BAPTISTA, 2002).

É nesse cenário loco-temporal que está inserido o bacharelado em Gestão de Serviços de Saúde (GSS) ofertado pela Universidade Federal de Minas Gerais (UFMG) desde 2009. Oferecendo cinquenta vagas semestralmente, esse curso é realizado no período noturno e com duração de nove semestres. Embora tenha sede na Escola de Enfermagem, sua proposta curricular é interdepartamental: além da unidade sede, três departamentos da Faculdade de Ciências Econômicas (Face) e um departamento da Faculdade de Medicina também participam dessa graduação desde a sua geração em 2007/2008 (UFMG, 2013).

Seu caráter inovador e incerto de nova graduação corrobora o cenário que $o$ circunscreve, e, como consequência, se formam diferentes concepções acerca da área do conhecimento a qual pertence o curso de GSS. Tal diversidade de perspectivas cria tensões quando o debate acerca da identidade do curso é levantado. No entanto, são sempre inconclusivos. A situação ainda é, desde os estudos de Ide e Schneck (1998), um dos desafios do sistema educacional de nível superior no Brasil, pois depende dessa identidade profissional coletiva o desenvolvimento e aprimoramento do curso de GSS e, consequentemente, seu sucesso em responder às necessidades sociais. Também se constitui como algo comum, já que todo campo científico passa por momentos de debates e conflitos, na tentativa de se construir consensos (FERREIRA; CUNHA; BASTOS, 2015).

Considerando a construção identitária de GSS e a experiência acumulada ao longo dos seus seis anos de implementação, pretende-se aqui encontrar indicações nas versões de 2008 e 2013 do Projeto Pedagógico de Curso (PPC) ${ }^{1}$ acerca de quais caminhos a GSS tem trilhado e com qual área de conhecimento é mais relacionada. Longe de findar essa discussão no cotidiano do curso, este estudo tem por objetivo estimular e colaborar com essas discussões identitárias, até então restritas às práticas discursivas. 


\section{Metodologia}

Trata-se de uma pesquisa documental, considerada como "um procedimento que se utiliza de métodos e técnicas para a apreensão, compreensão e análise de documentos [...]" (SÁ-SILVA; ALMEIDA; GUINDANI, 2009 , P. 4). Para Flick (2009), analisar documento é um modo de não ser intrusivo no campo de pesquisa, embora seja igualmente rico como outros métodos, uma vez que permite ir além das perspectivas de atores do campo e abre novas perspectivas sobre os processos de que trata o documento.

Como suporte documental, escolheram-se as duas versões (2008 e 2013) do PPC de GSS com o intuito de considerar dois momentos distintos de criação e implementação dessa graduação. O PPC é visto neste estudo como materialização de construção coletiva, constituído de escolhas, interesses e compromissos da universidade e sua comunidade para com toda a sociedade (PANASIEWVICZ ET AL., 2012; VENANCIO; DARIDO, 2012). Também serão considerados documentos auxiliares oficiais, como as Diretrizes Curriculares Nacionais (DCN) de cursos de graduação em administração e produções científicas acerca das graduações em saúde coletiva, já que suas DCN estão em processo de construção por parte da sociedade civil organizada, liderada pela Associação Brasileira de Saúde Coletiva (Abrasco).

Os PPCs do curso de GSS são documentos oficiais públicos e seu acesso é arquivo aberto (FLICK, 2009). Tal classificação é necessária para situar, nesta pesquisa, os documentos utilizados e para assegurar a qualidade dos mesmos. Além disso, os PPCs não se constituem como um pacote de informações prontas, mas sim como "dispositivos comunicativos metodologicamente desenvolvidos" (FLICK, 2009, P. 234) em um contexto sócio-histórico intencionado pelos atores nele envolvidos.

A ritualística apresentada por Sá-Silva,
Almeida e Guindani (2009) para a pesquisa documental envolve cinco dimensões transversais a esse tipo de procedimento: contexto, autor, autenticidade, natureza do texto e lógica interna do documento. Portanto, ao chegar à análise em si, onde serão produzidos, reelaborados e criados conhecimentos e novas formas de compreensão dos fenômenos, o pesquisador deve apresentar coerência ao questionamento científico e historicidade do objeto de pesquisa.

A partir do embasamento apresentado, verificou-se o que consta nas versões do PPC que esteja relacionado às perspectivas das vertentes identitárias construídas no cotidiano do referido curso, levando-se, assim, em consideração o contexto que permeia o suporte documental.

\section{Resultados e discussão}

A primeira versão do $\mathrm{PPC}$, datada de 2008, foi constituído como documento-base para a legitimação do curso na UFMG pelo Programa de Apoio ao Plano de Reestruturação e Expansão das Universidades Federais (Reuni) (UFMG, 2008). Já a segunda versão, foi revisada e atualizada em 2013, mesmo ano de avaliação e conceituação do referido curso de graduação pelo Ministério da Educação.

Os resultados serão apresentados juntamente com as vertentes identitárias reconhecidas na experiência dos autores. Sendo assim, a discussão acompanhará a transversalidade das dimensões, não se limitando, portanto, apenas ao corpo do texto presente nos PPCs.

\section{GSS como pertencente à área da administração}

Por essa vertente, o curso de GSS compete à área da administração, sob o código 60200006 (BRASIL, 2014). O embasamento 
2 Resposta dada pelo Conselho Regional de Administração de Minas Gerais a um ex-estudante do curso de GSS por e-mail e compartilhado nas redes sociais em 11/03/2014. dessa vertente remete-se à ligação histórica entre os cursos denominados de gestão

- Gestão Hospitalar, Gestão Ambiental

e Gestão Pública, como exemplos - e o campo da administração. Segundo Rodrigues (2010), gestão provém do latim gestione (ato de gerir, gerência, administração) e, portanto, pode ser considerado como sinônimo de administração. A corroboração dessa vertente é apoiada na Resolução Normativa do Conselho Federal de Administração n.o 426, de 15 de agosto de 2012, que regulamenta o registro profissional de cursos superiores de tecnologia e de bacharelados em determinada área da administração, sob a apreciação dos conselhos regionais. Essa legislação abre portas para a inserção de GSS no rol de graduações da área da administração, apesar de ter denominação de curso superior de tecnologia.

A presença da administração como campo central do conhecimento se faz nas duas versões do PPC, indicando a manutenção intencional dessa perspectiva na história do curso de GSS. Foi possível perceber reflexos dessa escolha no currículo estruturado para a formação do gestor, onde as disciplinas optativas foram separadas por quatro temáticas, sendo três delas relacionadas à Faculdade de Ciências Econômicas, unidade responsável pela oferta da graduação em administração na UFMG. Outro destaque que corrobora esse aspecto são as competências elencadas para o formado em GSS, onde as genéricas são relacionadas ao administrador e as específicas vinculadas ao perfil de um profissional de saúde que analisa o sistema e os serviços de saúde (UFMG, 2008, P. 11, 2013, P. 17).

No entanto, na versão de 2013, aparece a seguinte afirmação:

A orientação curricular do Curso de Gestão de Serviços de Saúde contempla as competências gerais definidas para os Cursos de Graduação da área da saúde [...]. (UFMG, 2013, P. 17).

E no decorrer dessa versão do PPC, não há citação das competências definidas para os cursos de graduação em administração (BRASIL, 2005). Já na versão de 2008 , seu uso está explicitado em

[...] foram consideradas apropriadas as bases conceituais sobre competência do curso de graduação em Administração e a proposta pedagógica do Curso de Enfermagem. (UFMG, 2008, P. 9).

Então, em algum momento do processo de construção do novo PPC, os saberes administrativos foram, em parte, retirados do bojo formativo desse futuro profissional que está sendo formado.

Contemporaneamente, a formação do gestor de serviços de saúde pela vertente da administração vem encontrando dificuldade no que se refere à oferta de disciplinas optativas dos departamentos correlatos, conforme percebido no gráfico 1, em que a relação de disciplinas previstas no PPC de 2013, no campo administrativo, é substancialmente inferior se comparado com as disciplinas da área da saúde. É possível que haja relações entre a diminuição do papel da administração no PPC com os problemas de oferta de vagas em disciplinas dessa área. Outra dificuldade encontrada foi a resposta dada em consulta feita por estudantes do curso em março de 2014, quando o Conselho Regional de Administração negou o pedido de registro profissional, uma vez que há o entendimento que apenas o curso superior de tecnologia Gestão de Serviços de(a) Saúde é autorizado pela Resolução Normativa n. 374 do Conselho Federal de Administração e que o bacharelado de GSS não pertence ao campo da administração ${ }^{2}$. 
Gráfico 1. Porcentagem de disciplinas optativas ofertadas em comparação com disciplinas optativas previstas no PPC, por semestre letivo

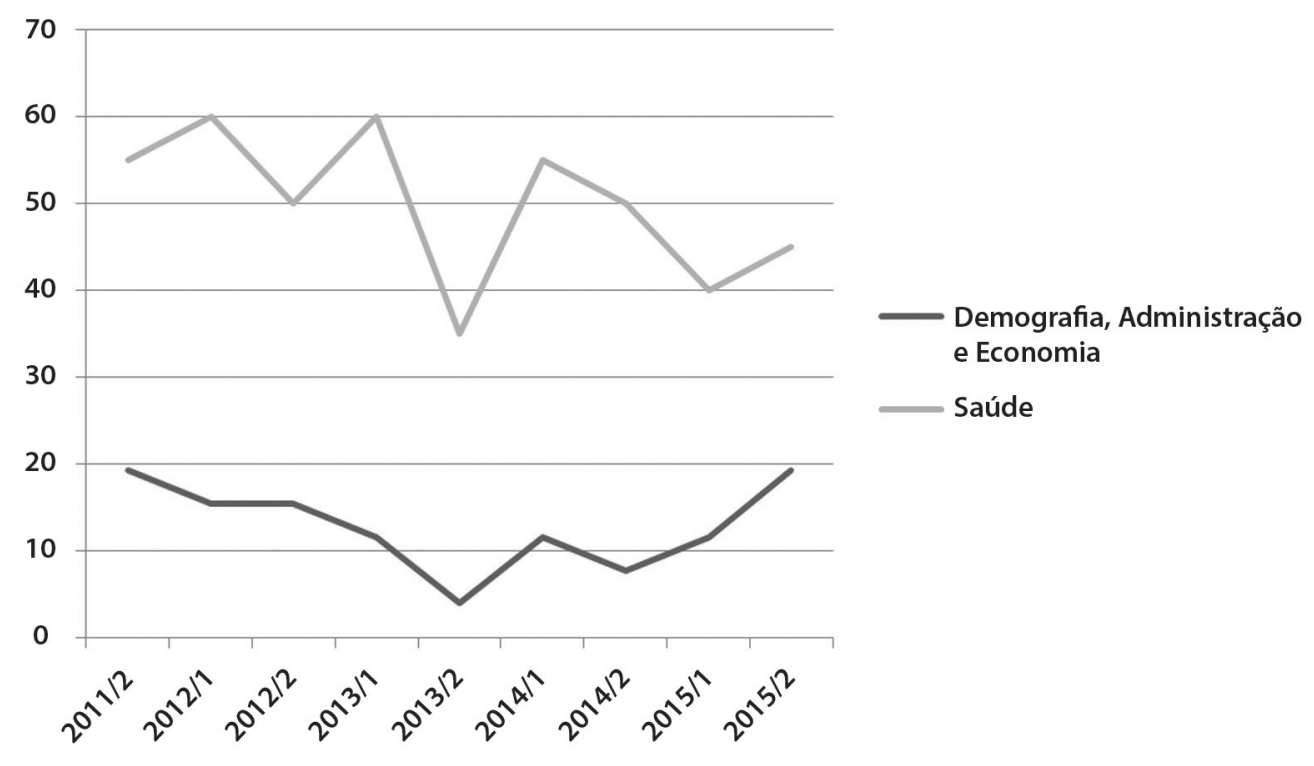

Fonte: Mapa de oferta de 2011/1 a 2015/2 da GSS/UFMG.

Nota: Sobre o semestre letivo 2013/2, não foi possível localizar mapa de oferta oficial lançado pelo Colegiado do Curso de GSS.

O trabalho interdisciplinar entre três unidades acadêmicas foi evidenciado em ambos os PPCs, já que

[...] foi criado o curso de Gestão de Serviços de Saúde, sediado na Escola de Enfermagem sendo desenvolvido, em parceria, com as Faculdades de Medicina e de Ciências Econômicas [...]. (UFMG, 2008, P. 5, 2013, P. 10).

Juntamente com essa integração, foram envolvidos seis departamentos, de Enfermagem Aplicada (Escola de Enfermagem), Medicina Social e Preventiva (Faculdade de Medicina), Ciências Administrativas, Economia, Demografia e de Ciências Contábeis (Faculdade de Ciências Econômicas). Mesmo não sendo possível, nesta pesquisa, compreender os motivos da constituição de tal cenário, é possível perceber a predominância dos campos correlatos à administração e os saberes sanitários como tema-ênfase, à luz do que acontece com outros cursos, tais como Gestão de Agronegócios ou Gestão Hospitalar. Há um núcleo de conhecimentos próprios da administração conjugado com conhecimentos específicos de determinada área, como evidenciado por outros trechos do PPC em "objeto de trabalho é a administração em saúde" (UFMG, 2008, P. 6, 2013, P. 11); "proposta de formação interdisciplinar de um profissional para a administração de sistema e serviços de saúde" (UFMG, 2008, P. 5, 2013, P. 10).

A área da administração é contemplada desde o nome do curso, modificado em 2010 para Gestão de Serviços de Saúde, até o núcleo de competências a serem desenvolvidas, uma vez que é baseado no perfil dos egressos da graduação em administração. Porém, no que se refere à implementação no cotidiano do curso de GSS, percebem-se dificuldades advindas da oferta de disciplinas, do não reconhecimento por parte dos órgãos 
representativos e de outros aspectos que fogem da análise estrita do PPC.

\section{GSS como pertencente à área da saú- de coletiva}

Nessa perspectiva, a GSS está classificada com outras novas graduações em saúde no País, como os bacharelados em Saúde Coletiva, inclusive com denominações semelhantes como Gestão em Saúde Coletiva Indígena, Gestão em Sistemas e Serviços de Saúde, Gestão em Saúde, Gestão em Saúde Coletiva, Gestão em Saúde Humana e Gestão em Saúde Ambiental. Na literatura especializada, são encontrados estudos que incluem o curso da UFMG na lista dos Cursos de Graduação em Saúde Coletiva (CGSC): Belisário et al. (2013), Castellanos et al. (2013), Ruela (2013), Kleinubing (2012) e Koifman e Gomes (2008) são alguns dos exemplos mais recentes de produções científicas. Além disso, está sendo realizada uma pesquisa sobre estágios curriculares dessa nova carreira no âmbito do Programa Ensinar com Pesquisa da Universidade de São Paulo, que também agrega a GSS como participante da pesquisa. Por essa vertente, o curso da UFMG contempla o tripé da saúde coletiva, área de conhecimento no 40600009 (BRASIL, 2014), ou seja, ciências humanas e sociais aplicadas à saúde, epidemiologia e políticas e planejamento em saúde (AKERMAN; FEUERWERKER, 2006).

Na gênese do curso de GSS, sua denominação era outra, possuindo semelhanças com o curso de graduação em Análise de Políticas e Sistemas de Saúde (atual bacharelado em Saúde Coletiva) da Universidade Federal do Rio Grande do Sul (UFRGS), a de "Curso de Graduação: Bacharelado em Análise de Sistema e Serviços de Saúde” (UFMG, 2008, P. 4).

Além disso, o movimento nacional de criação de novas graduações em saúde é utilizado como justificativa para a pertinência e necessidade de a UFMG se inserir nesse processo formativo nacional:
Há que se ressaltar um movimento nacional para criação do profissional de gestão em saúde nas universidades federais, tais como UFPA (Universidade Federal do Pará), UFBA (Universidade Federal da Bahia), UnB (Universidade de Brasília) e UFRGS além da UFMG. (UFMG, 2008, P. 7).

Atualmente, essas universidades reformaram seus cursos sob a denominação de bacharelado em Saúde Coletiva (UFBA, UFRGS e UnB - Campus Ceilândia) ou bacharelado em Gestão em Saúde (UnB - Campus Darcy Ribeiro). Apesar de não terem sido encontrados registros de tal iniciativa na UFPA, mas sim na Universidade Federal do Sul e do Sudeste do Pará (Unifesspa), percebe-se o movimento realizado pelos cursos considerados similares ao de GSS em direção à consolidação das graduações em Saúde Coletiva no País. Porém, ao analisar a versão de 2013, não foram encontradas citações que indicassem semelhanças entre a proposta da UFMG e outras iniciativas pelo Brasil. Verifica-se que a ruptura com o movimento nacional foi exposta no PPC pela supressão das experiências antes citadas. No entanto, objetivos, perfil do egresso, campo de atuação e demais características que delimitam o curso foram mantidas, ou seja, a ruptura não se fez estruturalmente no curso de GSS, mas apenas discursivamente.

A proposta do curso de GSS foi aprovada no contexto do Reuni com a premissa de antecipar a formação de um profissional de saúde apto para a gestão do sistema e dos serviços de saúde da pós-graduação para o nível de graduação. Tal formação se ancora na interdisciplinaridade e nas necessidades sociais (UFMG, 2008, 2013). O conjunto dessas afirmações é semelhante àquelas analisadas por Ruela (2013) em sua dissertação de mestrado. Segundo esse autor, argumentos apoiados na especificidade da gestão em saúde e na necessidade da constituição de um aporte próprio desse novo profissional são compartilhados pelos demais cursos 
de graduação em Saúde Coletiva. O Reuni também é citado tanto no estudo de Ruela (2013) como nas duas versões do PPC aqui analisadas como sendo uma política decisiva na criação e implementação dos cursos, imprimindo força e materialidade nesse desejo de formar tais profissionais. O seguinte trecho evidencia a proximidade de intenções com as demais graduações no País e reforça que o curso de GSS forma profissionais de saúde e não administradores:

Reforça-se, aqui, que a 'formação dos profissionais de saúde' no Brasil é um tema estratégico definido pela necessidade de qualificar e adequar o perfil necessário ao Sistema Único de Saúde [...]. Para fazer frente a esses desafios, o argumento de criação do Curso de Gestão de Serviços de Saúde teve como base a necessidade social de um profissional para preencher uma lacuna no mercado das 'profissões de saúde' [...]. (RUELA, 2013, P. 12, GRIFO NOSSO).

A interdisciplinaridade é enunciada no projeto do curso de GSS como um princípio a ser desenvolvido, conforme demonstrado no trecho a seguir.

De modo especial, o desenvolvimento do princípio da interdisciplinaridade configura-se como uma premissa no Curso de Gestão de Serviços de Saúde na busca do diálogo constante entre as áreas da Saúde, Economia, Administração, Demografia e Contabilidade para compreender a complexidade das políticas e organizações de saúde e propor ações de intervenção nesta realidade. (RUELA, 2013, P. 10).

Em análise de campo teórico feita por Spagnol (2005, P. 121), expõem-se as dificuldades em definir saúde coletiva por ser uma área que transcende as disciplinas e se constitui em campo de conhecimento pluralizado, feito por outras disciplinas-base como "a epidemiologia, as ciências sociais em saúde, o planejamento e a administração em saúde". A fim de complementar esse campo, atuam também outras disciplinas como, por exemplo, demografia, estatística e ciências biomédicas. Percebe-se a forte relação entre a definição da saúde coletiva com conceitos basilares da graduação em foco.

A vertente da saúde coletiva no curso possui apoio pela lógica científica em razão das diversas produções desenvolvidas que incluem GSS no movimento de formação de sanitaristas em nível de graduação. No entanto, não é mais aceita internamente, e as causas dessa negação vão além desta pesquisa documental. O que é entendido aqui é que há predominância dessa perspectiva tanto nos PPCs como na comunidade acadêmica, cujos argumentos de criação, manutenção e necessidade se assemelham a outros cursos de graduação em Saúde Coletiva.

\section{GSS como pertencente à área multidisciplinar}

A última vertente construída no curso de GSS é a que não considera essa nova graduação nem pertencente à área da administração - uma vez que fazer a gestão do campo da saúde requer mais que os instrumentos e conhecimentos administrativos - nem à área da saúde coletiva, por considerar que o bacharel nessa área tem atuação restrita ao subsistema público de saúde e não conjuga todas as competências necessárias para atender à necessidade de gestão da saúde no País. Para fins de classificação, entende-se que essa vertente se apoia na área multidisciplinar, pelo $\mathrm{n}^{\circ} 90000005$ (BRASIL, 2014). Por definição, multidisciplinaridade é a junção de saberes de diferentes áreas sem que haja, necessariamente, interconexão (ORNELAS; TEIXEIRA, 2015).

Considera-se o curso de GSS pioneiro no estado de Minas Gerais na formação de gestor de serviços de saúde, havendo semelhança apenas com o curso de Gestão em Sistema e Serviços de Saúde ofertado pela Universidade Federal do Rio Grande do Norte (UFRN) desde 2009. O movimento, 
nessa perspectiva, é criar um novo espaço entre as áreas de conhecimento que abarcam essas duas experiências de graduação em saúde.

Sob a vertente multidisciplinar da identidade do Curso de GSS, observou-se nos PPP analisados a intenção de transcender as outras perspectivas anteriores, em um esforço de ultrapassar o espaço de formação e atuação do administrador e do sanitarista. Como exemplo, o trecho de um dos projetos afirma que

o conhecimento do setor saúde tem se mostrado tão ou mais importante que o domínio na área da administração, resultando em escolhas de profissionais em saúde em detrimento de administradores para gerenciar serviços de saúde. $(2008$, P. 6).

Entendendo que administração não comporta todos os conhecimentos necessários para a formação desejada e que a saúde coletiva possui outros objetivos que não, estritamente, a gestão dos serviços de saúde, o curso de GSS vem como vanguardista de seu campo de atuação no sistema de saúde nacional. Tal visão de si mesmo também pode ser percebida com a adoção de referenciais de competências a partir das Diretrizes Curriculares Nacionais (DCN) para a Educação Profissional de Nível Técnico (UFMG, 2008, P. 10). À época da escrita do PPP já existiam DCNs tanto para as graduações em saúde como também para os cursos de administração, ou seja, já estavam definidas as bases para cursos como o de enfermagem. Mesmo assim, contendo citações de ambos os cursos no PPP como embasadores, o fato de não ter aderido a seus respectivos documentos legais pode indicar o desejo de se desvincular desses campos tradicionais considerados insuficientes para a formação do gestor de serviços de saúde. Fato também indicado no trecho a seguir:

Há, portanto, 'um direcionamento', a nosso ver, 'pouco adequado' de formação e aproveitamento 'dos profissionais de saúde', em decorrência da falta de um profissional graduado no mercado para a área administrativa do setor. (UFMG, 2013, P. 11, GRIFO NOSSO).

A partir desse excerto, é perceptível a indicação de fragilidades nas áreas da saúde e da administração para justificar o advento de um novo profissional, apto para gerir o setor saúde sem prejudicar outros já existentes. Tal campo de formação estaria formalizado nas classificações da Capes na área multidisciplinar. No entanto, não foi possível a definição da especialidade a qual pertence, se sociais e humanidades, engenharia/tecnologia/gestão ou saúde e biológicas.

A defesa da vertente aqui chamada de multidisciplinar se ancora no ineditismo da proposta de formar gestores de serviços de saúde com capacidades técnicas mais inovadoras para suprir a demanda do setor saúde no País. Nesse movimento, o curso de GSS se destaca e ao mesmo tempo se isola de outros cursos de graduação que poderiam ampliar o poder de criar outra área de saberes, tão almejada por essa perspectiva.

\section{Considerações finais}

Esta pesquisa documental objetiva expandir a visão sobre realidades antes restritas às esferas cotidianas do curso de GSS. Ao reconduzir esse debate para o alcance nacional e científico, aprimoram-se os argumentos utilizados e confere-se qualidade na construção da identidade de nova graduação em saúde.

A constituição de três grupos cujas opiniões divergem entre si pode gerar tanto o desmantelamento como a união da comunidade que sustenta o curso - o que vai ditar essa história será o modo como se conduzirão as discussões sobre o assunto. Isso se faz mais necessário quando se encara a perspectiva interdisciplinar de GSS. Sendo 
assim, todas as visões (baseadas em diferentes disciplinas) precisam ser reconhecidas como legítimas, sendo possível, dessa forma, a troca de experiências com a finalidade consensual do processo identitário. Sobre isso, é importante frisar que a Faculdade de Filosofia e Ciências Humanas (Fafich/ UFMG), unidade acadêmica de referência para temáticas relacionadas a um dos eixos da saúde coletiva, não foi incluída na conformação do curso de GSS em 2007/2008.

Outro aspecto encontrado aqui foi a fragilidade, pela lógica acadêmica, nas vertentes da administração e multidisciplinar. Ambas possuem escassos trabalhos científicos que os corroboram e não existe apoio nacional para sua efetivação em determinado campo. Por outro lado, a vertente da saúde coletiva é amparada tanto por produções como pela organização da sociedade para reconhecimento desse perfil de sanitarista como décima quinta profissão de saúde. Considerando que a GSS é um curso novo e que luta por seu espaço no mundo do trabalho, é coerente que agregue forças com o movimento nacional a fim de fortalecer as próprias bases.

Portanto, fica o convite ao conflito. Conflitos estes que, antes de qualquer coisa, darão a dizibilidade necessária aos discursos até então escondidos nas linhas da rotina universitária. Pesquisas devem ser feitas e é necessária a participação em fóruns. Desafios serão encontrados na luta pelo fortalecimento dessa nova profissão que deseja continuar a construção do sistema nacional de saúde brasileiro e do direito à saúde de qualidade.

\section{Referências}

\section{AKERMAN, M.; FEUERWERKER, L. Estou me formando (ou eu me formei) e quero trabalhar: que oportunidades o sistema de saúde de oferece na Saúde Coletiva? Onde posso atuar e que competências preciso desenvolver?. In: CAMPOS, G. W. S. et al. (Org.). Tratado de Saúde Coletiva. São Paulo: Hucitec; Rio de Janeiro: Fiocruz, 2006. p. 183-200. \\ BAPTISTA, M. T. D. S. O estudo de identidades individuais e coletivas na constituição da história da psicologia. Memorandum, Belo Horizonte, v. 2, p. 31-38, abr. 2002. Disponível em: <http://www.fafich.ufmg. br/ memorandum/artigos02/artigo04.pdf>. Acesso em: 13 jun. 2015.}

BELISARIO, S. A. et al. Implantação do curso de graduação em saúde coletiva: a visão dos coordenadores. Ciênc. saúde coletiva, Rio de Janeiro, v. 18, n. 6, p. 1625-1634, jun. 2013. Disponível em: <http://www. scielo.br/scielo.php?script=sci_arttext\&pid $=$ S1413$81232013000600014 \& \operatorname{lng}=\mathrm{en} \& \mathrm{nrm}=\mathrm{iso}>$. Acesso em: 24 abr. 2015.

BOSI, M. L. M.; PAIM, J. S. Graduação em Saúde Coletiva: limites e possibilidades como estratégia de formação profissional. Ciênc. saúde coletiva, Rio de
Janeiro, v. 15, n. 4, p. 2029-2038, jul. 2010. Disponível em: <http://www.scielo.br/scielo.php?script=sci arttext\&pid=S1413-81232010000400017\&lng=en\&nrm=i so>. Acesso em: 13 jun. 2015.

BRASIL. Ministério da Educação. Conselho Nacional de Educação (CNE). Resolução n. 4, de 13 de julho de 2005. Institui as diretrizes curriculares nacionais do curso de graduação em administração, bacharelado, e dá outras providências. Câmara de Educação Superior, 2005. Disponível em: <http://portal.mec.gov.br/cne/arquivos/ pdf/rces004_05.pdf>. Acesso em: 14 jun. 2015.

Ministério da Educação. Coordenação de Aperfeiçoamento de Pessoal de Ensino Superior (Capes). Tabela de áreas de conhecimento/avaliação, 2014. Disponível em: <http://www.capes.gov.br/ avaliacao/instrumentos-de-apoio/tabela-de-areas-doconhecimento-avaliacao>. Acesso em: 13 jun. 2015.

CASTELLANOS, M. E. P. et al. Estudantes de graduação em Saúde Coletiva: perfil sociodemográfico e motivações. Ciênc. saúde coletiva, Rio de Janeiro, v. 18, n. 6, jun. 2013. Disponível em: < http://www. scielosp.org/scielo.php?script=sci_arttext\&pid=S1413$81232013001400017 \& \operatorname{lng}=\mathrm{en} \& \mathrm{nrm}=\mathrm{iso}>$. Acesso em: 23 
maio 2015

CONSELHO FEDERAL DE ADMINISTRAÇÃO (CFA). Resolução normativa CFA $n^{\circ} 426$, de 15 de agosto de 2012. Altera a resolução normativa CFA n ${ }^{\circ} 373$, de 12 de novembro de 2009, e dá outras providências. Disponível em: <http://www.cfa.org.br/institucional/legislacao/ resolucoes/2012/RN000812.pdf/view>. Acesso em: 13 jun. 2015.

FERREIRA, J.; CUNHA, C. L. F.; BASTOS, L. L. O campo científico da Saúde Coletiva: apontamentos para o debate para a formação da pós-graduação stricto sensu. Rev. Eletron. Gestão Saúde, Brasília, v. 6, n. 2, p. 12541266,2015

FLICK, U. Introdução à pesquisa qualitativa. Porto Alegre: Artmed, 2009.

IDE, C. A. C.; SCHNECK, C. A. Desenvolvimento discente e identidade profissional de enfermagem: os sistemas de conceitos como mediadores do aprendizado. Rev. bras. enferm., Brasília, v. 51, n. 3, p. 403-416, set. 1998. Disponível em: <http://www. scielo.br/scielo.php?script=sci_arttext\&pid=S003471671998000300006\&lng=en\&nrm=iso >. Acesso em: 24 maio 2015 .

KOIFMAN, L.; GOMES, L. N. A graduação em Saúde Coletiva: um debate ou uma realidade? Rev. bras. educ. med., Rio de Janeiro, v. 32, n. 4, p. 417-418, dez. 2008. Disponível em: <http://www. scielo.br/scielo.php?script=sci_arttext\&pid=S0100$55022008000400001 \& \operatorname{lng}=$ en\&nrm=iso $>$. Acesso em: 23 maio 2015

KLEINUBING, N. V. O bacharel em Saúde Coletiva. 2012. 33 f. Dissertação (Programa de Mestrado Profissional em Saúde e Gestão do Trabalho) - Universidade Vale do Itajaí, Itajaí, 2012.

LIMA, A. M. M. Graduação em gerontologia: da inovação pedagógica à formação da identidade profissional do gerontólogo. Rev. Kairós, São Paulo, caderno temático 4, p. 19-31, ago. 2009.

LIMA, R. M. S. Projeto Político-Pedagógico na perspectiva freireana: participação e diálogo. 2011. 150

f. Dissertação (Mestrado em Educação: Currículo) Pontifícia Universidade Católica de São Paulo (PUC-SP), São Paulo, 2011. Disponível em: <http://www.sapientia. pucsp.br//tde_busca/arquivo.php?codArquivo=13862>. Acesso em: 12 mar. 2015.

MALACRIDA, V. A. et al. A identidade do curso de pedagogia: uma investigação via história oral. Colloquium Humanarum, Toledo, v. 10, n. spec., p. 695704, jul./dez. 2013.

MARTINS, C. L. Desvelando a identidade da pósgraduação em saúde pública. 1999. 234 f. Tese (Doutorado em Saúde Pública) - Universidade de São Paulo (USP), Faculdade de Saúde Pública, São Paulo, 1999.

ORNELAS, A. L.; TEIXEIRA, M. G. C. Intersetorialidade ou diálogos setoriais?: reflexões a partir da experiência do Projeto Teias-Escola Manguinhos, Rio de Janeiro. Saúde Debate, Rio de Janeiro, v. 39, n. 106, jul./set. 2015.

PANASIEWICZ, R. et al. Educação e cidadania: a formação humanista da juventude nos projetos pedagógicos. Horizonte, Belo Horizonte, v. 10, n. 26, abr./jun. 2012. Disponível em: <http://periodicos. pucminas.br/index.php/horizonte/article/view/P.21755841.2012v10n26p399>. Acesso em: 12 mar. 2015.

ROSA, S. S. Gestão estratégica e currículo: (re) construindo a identidade do curso de Pedagogia a partir das demandas sociais. Rev. E-Curriculum, São Paulo, v. 3, n. 1, dez. 2007. Disponível em: <http://revistas.pucsp. br/index.php/curriculum/article/viewFile/3200/2122>. Acesso em: 13 jun. 2015.

RODRIGUES, R. C. Uma proposta de metodologia de trabalho baseada em contabilidade gerencial para uma empresa de pequeno porte situada no interior do estado do Ceará. 2010. 53 f. Monografia (Bacharelado em Ciências Contábeis) - Faculdade Lourenço Filho, Fortaleza, 2010.

RUELA, H. C. G. A formação de sanitaristas e os cursos de graduação em saúde coletiva no Brasil. 2013. 134 f. Dissertação (Mestrado Profissional em Educação Profissional em Saúde) - Escola Politécnica de Saúde Joaquim Venâncio, Fundação Oswaldo Cruz, Rio de 
Janeiro, 2013.

SÁ-SILVA, J. R.; ALMEIDA, C. D.; GUINDANI, J. F.

Pesquisa documental: pistas teóricas e metodológicas.

Rev. Bras. Historia Cien. Sociais, São Leopoldo, v. 1, n. 1, p. 1-15, jul. 2009.

SOUSA NETO, A. R. Em busca de uma identidade: o curso de Pedagogia da UFG. Rev. Eletron. Educação do Curso Pedagogia Campus Avanç. Jataí UFG, Jataí, v. 1, n. 1, jan./jul., 2005. Disponível em: <http://www.revistas. ufg.br/index.php/ritref/article/viewFile/20395/11883>. Acesso em: 13 jun. 2015.

SPAGNOL, C. A. (Re)pensando a gerência em enfermagem a partir de conceitos utilizados no campo da Saúde Coletiva. Ciênc. saúde coletiva, Rio de Janeiro, v. 10, n. 1, p. 119-127, mar. 2005. Disponível em: <http:// www.scielo.br/scielo.php?script=sci_arttext\&pid=S1413$81232005000100019 \& \operatorname{lng}=$ en\&nrm=iso $>$. Acesso em: 29 maio 2015 .

\section{UNIVERSIDADE FEDERAL DE MINAS GERAIS}

(UFMG). Projeto pedagógico do curso de Gestão de Serviços de Saúde, 2008.
Projeto pedagógico do curso de Gestão de Serviços

de Saúde, 2013.

VEIGA, I. P. A. Projeto político-pedagógico da escola: uma construção possível. 14. ed. Campinas: Papirus, 2002.

Inovações e projeto político-pedagógico: uma relação regulatória ou emancipatória?. Cad. CEDES, Campinas, v. 23, n. 61, p. 267-281, dez. 2003. Disponível em: $<$ http://www.scielo.br/scielo.php?script=sci arttext\&pid=S0101-32622003006100002\&lng=en\&nrm= iso>. Acesso em: 16 mar. 2015.

VENANCIO, L.; DARIDO, S. C. A educação física escolar e o projeto político pedagógico: um processo de construção coletiva a partir da pesquisa-ação. Rev. bras. educ. fís. esporte, São Paulo, v. 26, n. 1, mar. 2012. Disponível em: <http://www.scielo. br/scielo.php?script=sci_arttext\&pid=S180755092012000100010\&lng=en\&nrm=iso $>$. Acesso em: 17 mar. 2015.

Recebido para publicação em julho de 2015

Versão final em novembro de 2015

Conflito de interesses: inexistente

Suporte financeiro: não houve 